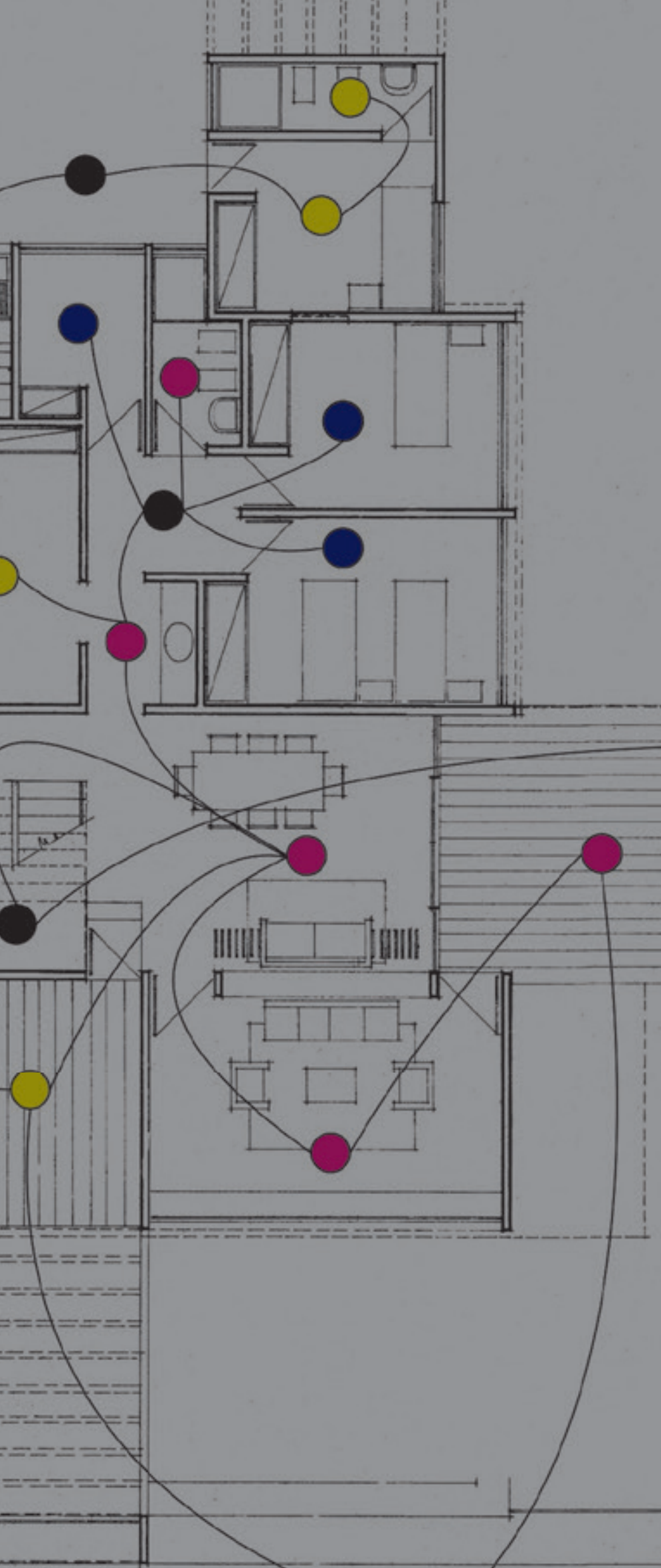

1. Este artigo se apóia nos resultados da pesquisa de mestrado de Maryá Aldrigue, vinculada ao Programa de Pós-Graduação em Arquitetura e Urbanismo da Universidade Federal do Rio Grande do Norte (PPGAU/UFRN), sob a orientação de Nelci Tinem e co-orientação de Edja Trigueiro.

2. Arquiteta e urbanista, doutoranda do Programa de Pós-Graduação em Arquitetura e Urbanismo da USP (IAU) São Carlos),mestre em Arquitetura e Urbanismo pela UFRN. E-mail: maryaaldrigue@yahoo.com.br.

3. Arquiteta e urbanista pela UnB, pós-doutora pela UFBA,doutora em História da Arquitetura e História Urbana pela ETSAB-UPC, mestra em Planejamento Urbano e Regional pela UFRGS. Atualmente é professora associada do Departamento de Arquitetura e do Programa de Pós-Graduação da UFPB, e colaboradora do PPGAU/UFRN. E-mail: ntinem@uol.com.br.

DOI:10.5752/P.23161752.2014v21n29p118 


\title{
A ORGANIZAÇÃO ESPACIAL MODERNA E SEUS INVÓLUCROS'
}

\author{
THE MODERN SPATIAL ORGANIZATION AND ITS BUILDING SHELLS
}

LA ORGANIZACIÓN ESPACIAL MODERNAY SUS ENVOLTORIOS

\author{
Maryá de Sousa Aldrigue ${ }^{2}$ \\ NelciTinem ${ }^{3}$
}

\section{Resumo}

O artigo investiga as correspondências existentes entre a organização espacial e os invólucros construídos de 19residências edificadasna década de 1970, em João Pessoa-PB, sob a égide do vocabulário moderno, que ainda predominava no Brasil, embora compartilhando espaço na cena urbana com outras tendências arquitetônicas. Essas residências foram originalmente classificadas em cinco categorias definidas por seus atributos formais e técnicos. Procurou-se verificar se essa taxonomia corresponde a categorias definidas pela configuração espacial. Os resultados apontaram que não existem evidências de relação de reciprocidade entre invólucro e suas respectivas organizações espaciais.

Palavras-chave: Arquitetura residencial. João Pessoa. Década de 1970. Organização espacial.

\begin{abstract}
This paper investigatesthe correspondencesexistingbetween thespatial organizationand the shells of nineteenresidences builtin the 1970sin João Pessoa(PB, Brazil), when the vocabulary of modern architecture still prevailed in Brazil though sharing the urban scene with other architectural trends. These dwellings were originally classified in five categories defined according to the form of their building shells and to their prevailing construction techniques. We aim to determine whether this taxonomy corresponds to distinct modes of spatial configuration. Results pointed out that there is no evidence of a reciprocal relationship between the formal look of the built shells and their respective spatial structures.
\end{abstract}

Keywords: Domestic space. João Pessoa. 1970s. Spatial organization.

\begin{abstract}
Resumen
Este artículo investiga la correspondencia existente entre la organización espacial y la caja mural que la envuelve de diecinueve viviendas construidas en la década de 1970 en João Pessoa (PB, Brasil), cuyo vocabulario moderno seguía siendo predominante en Brasil, aunque compartiera espacio en la escena urbana con otras tendencias arquitectónicas. Estas casas fueron clasificadas originalmente en cinco categorías definidas por sus atributos formales y técnicos. Tratase de advertir si esta taxonomía corresponde a las categorías definidas por la configuración espacial. Los resultados mostraron que no hay evidencia de reciprocidad entre la caja mural construida y su organización espacial.
\end{abstract}

Palabras clave: Arquitectura residencial. João Pessoa. Años 1970. Organización espacial. 


\section{Introduzindo}

A noção de espaço como componente essencial da arquitetura não é nova. Estudos que enfocam esse aspecto - arquitetura como relações entre barreiras (sólidos) e permeabilidades (vazios) - começaram a difundir-se principalmente a partir do século passado. Tratar o espaço, com base sua dimensão topológica, ${ }^{4}$ como fonte de conhecimento sobre padrões sociais, levando a fundo a noção de arquitetura como expressão da organização social e, principalmente, trazendo métodos sistemáticos de análise, representação e quantificação que se apliquem aos mais diversos artefatos arquitetônicos ou urbanos é a contribuição da análise sintática do espaço (ASE). Assim, configurações espaciais aparentemente distintas podem ser relacionadas e comparadas com base nos métodos próprios da sintaxe espacial ${ }^{5}$ (HILLIER; HANSON, 1984).

A maioria dos estudos sobre arquitetura moderna enfoca o invólucro construído de edifícios (tratamento de superfícies, estrutura construtiva, materiais e técnicas), considerando que sua organização espacial, quando tratada, tende a ser considerada em termos de geometria e função (número, área, forma e adjacências de espaços projetados para tal uso). Argumentamos que uma avaliação da maneira como uma tendência arquitetônica é adotada e encontra expressão pode ser inspirada por uma análise que pode ir além da natureza física dos invólucros, especialmente no que diz respeito a edifícios residenciais - os "edifícios mais complexos", na opinião de alguns pesquisadores, como Hanson(1998).

Entre as possibilidades de estudo, o edifício pode ser compreendido e analisado sob dois aspectos: (1) como invólucro construído, baseado nas qualidades arquitetônicas decorrentes da técnica construtiva e da intenção estética;e (2) como organização espacial, em que o arranjo entre as partes, ou seja, entre os espaços, e a relação entre eles define a natureza do todo. Este segundo aspecto estabelece como os ambientes se conectam entre si, induzindo certos padrões espaciais de uso e interações entre grupos de usuários (moradores, visitantes e empregados, no caso das residências). Nesse sentido, a organização espacial é investigada por meio do grau de relacionamento entre os ambientes (quantificado a partir de suas relações topológicas), como estão sequenciados e conectados, ou seja, quem se liga a quem, se diretamente ou indiretamente, através de espaços intermediários.

Assumindo que invólucro construído e espaço representam duas dimensões distintas da arquitetura(ainda que indissociáveis e interdependentes), este estudo enfoca as propriedades espaciais intrínsecas mediante as quais o espaço doméstico é estruturado em uma amostra de 19residências unifamiliares construídas em João Pessoa-PB, nos anos 1970(quando a difusão do vocabulário moderno já compartilha espaço na cena urbana com outras tendências arquitetônicas). O objetivo é discutir as relações entre invólucro construído, considerando suas diversas manifestações, e organização espacial, a fim de verificar se um maior ou menor vinculo à linguagem da arquitetura moderna brasileira presente nas superfícies construídas
4. A topologia é um ramo da Matemática que estuda propriedades como a posição, modo de conexão, relações de vizinhança e adjacência, entre outras, e não as propriedades dimensionais ou métricas abordadas pela geometria.

5. Os termos "sintaxe espacial," "análise sintática", "análise sintática do espaço" e "análise configuracional", oriundos da Teoria da Lógica Social do Espaço (HILLIER; HANSON, 1984), são utilizados neste trabalho como sinônimos. 
corresponde a mais ou menos evidências do modernismo, considerando as estruturas espaciais. Nesse contexto, as duas dimensões podem ou não corresponder entre si, ou seja, a aparência pode ou não ser representativa do espaço que envolve, de maneira que invólucros distintos podem guardar organizações espaciais semelhantes.

\section{Arquitetura(s)na década de 1970}

A produção posterior a 1960, que se convencionou chamar de "pós-Brasília", foi obscurecida por uma interpretação historiográfica equivocada que negava a existência de uma arquitetura de qualidade nesse período, diante dos limites impostos pelo regime ditatorial implantado com o golpe de 1964, marcado pela ausência de discussões e críticas sobre a produção nacional e pelo distanciamento do debate internacional.

A situação começou a se modificar a partir do fim da década de 1980, quando ganharam visibilidade as organizações que se dedicavam à documentação e proteção do patrimônio moderno e, principalmente, as pesquisas desenvolvidas pelos programas de pós-graduação, que começaram a tratar do tema, provendo novas versões, estendendo os estudos à produção contemporânea e alargando os limites da arquitetura moderna considerando outros centros urbanos, inclusive os Norte e Nordeste brasileiros, em busca de um panorama mais amplo, que inclui o processo de difusão dessa arquitetura e preenche as lacunas relativas às motivações, agentes e influências regionais.

Nesse sentido, a produção arquitetônica da década de 1970, no Brasil, diante da complexa conjuntura nacional, foi marcada pela perda de prestígio da arquitetura moderna brasileira (responsável por construir a imagem oficial e canônica dessa produção entre as décadas de 1930 e 1960), com base nas interpretações vinculados à ideia de uma crise deflagrada em meados dos anos 1960, que repercutiram e se materializaram pelo pluralismo de expressões arquitetônicas (BASTOS, 2007). A heterogeneidade dessa produção apontava para uma série de experiências que, em relação ao invólucro,expunha, de um lado, a continuidade da linguagem moderna das décadas anteriores e, de outro, construções que indicavam alternativas de transformação desse vocabulário, inclusive adotando elementos do passado colonial, muitas vezes reinterpretados de modo equivocado.

Esse mesmo pluralismo caracteriza a experiência arquitetônica de João Pessoa na década de 1970. Em um trabalho de levantamento e análise dessa produção, Araújo (2010) identificou cinco vertentes associadas à arquitetura residencial unifamiliar que privilegiavam atributos formais e técnicos (elementos de fachada, configuração volumétrica, técnicas e materiais construtivos) (FIG. 1).Quatro dessas vertentes correspondem a experiências de reinterpretação/adaptação à demanda contemporânea da arquitetura moderna brasileira do período 1940-1960: (1) experiências de continuidade em relação ao legado moderno brasileiro, associado ao vocabulário da produção anterior a 1960; (2) experiências com extensa utilização do concreto 
armado, ligadas àprodução paulista moderna pós-1960; (3) experiências de racionalização e pré-fabricação, realizadas com base em elementos pré-fabricados, visando a alguma inovação plástica e técnico-construtiva, em uma tentativa de incorporar um novo público, de faixa de renda média, que passa a contratar os serviços profissionais do arquiteto; (4) experiências de adequação ao clima quente e úmido da região.Essas vertentes agrupam 87 projetos (75\%) do total de 116 analisados. O restante (25\%) pertence ao grupo denominado "residências híbridas" "que apesar de se apoiarem em recursos modernos abundantemente difundidos utilizam em muitos casos elementos de uma arquitetura equivocadamente chamada de neocolonial" (ARAÚJO; TINEM; COTRIM, 2010).

\section{A organização espacial como suporte}

As profundas transformações conduzidas pelo movimento moderno não ficaram restritas aos aspectos plásticos e volumétricos do invólucro construído. A arquitetura moderna projetou e induziu mudanças também no interior dos edifícios conforme a realidade social se transformava. Assim, os arquitetos modernos propuseram para o espaço novas interpretações que viriam a mudar o modo de concepção e, principalmente, a compreensão de seu significado para a experiência arquitetônica, como prática e disciplina. Fazia parte desse ideário a crença de que se podia modificar a sociedade (e o homem) a partir de uma rees-
Figura 1 • Pluralismo na produção arquitetônica de João Pessoa nos anos 1970. (1) Exemplo de "legado moderno brasileiro" - Res. Acácio Colaço de Caldas Barros (1978); (2) exemplo de "arquitetura paulista" - Res. Haroldo Coutinho de Lucena (1979); (3) exemplo de "experiência de racionalização e pré-fabricação" - Res. Luís Carlos Carvalho (1976); (4) exemplo de "residência híbrida" - Res. Antônio Queiroga Lopes (1976); (5) exemplo de "experiência de adequação ao clima" Res. Jair Cunha (1979).

Fonte: Araújo, 2010 (editado pelas autoras).
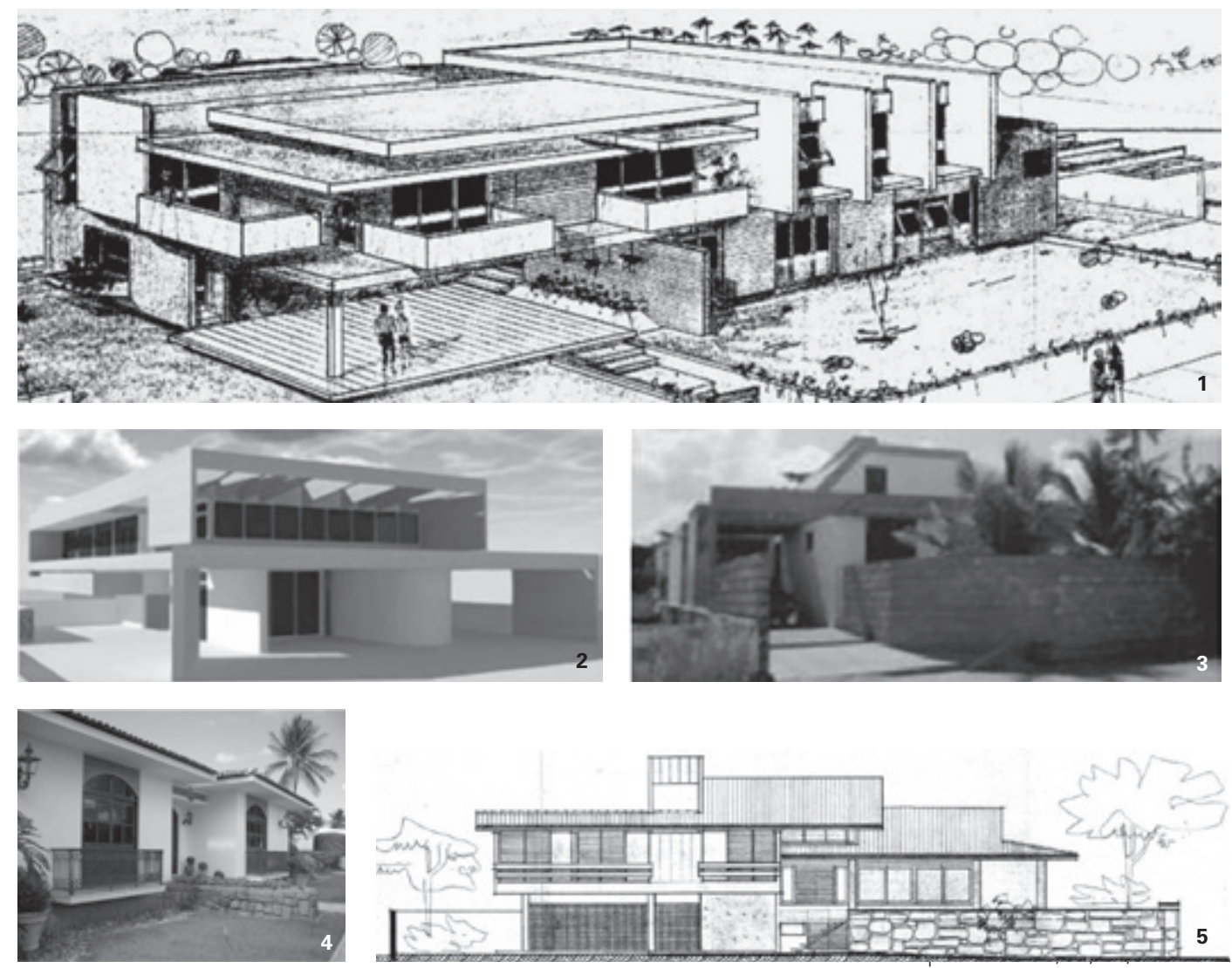
truturação da organização espacial mediante a interpretação de um programa. A casa era então projetada segundo procedimentos racionais de ordenamento das atividades em unidades espaciais, agrupadas, de acordo com as atividades exercidas, em núcleos distintos (setores). Com efeito, a arquitetura moderna transformou definitivamente os esquemas espaciais precedentes, constituindo um "modelo" de concepção. Essa perspectiva desloca o foco central da discussão do terreno da composição formal para o da organização espacial.

O edifício moderno foi concebido para ser experimentado espacialmente. Em outras palavras, traduz uma experiência inseparável do movimento. Compreender como o sistema de barreiras e permeabilidades, ou seja, as áreas acessíveis ou não, determina esse movimento é fundamental para compreender a experiência espacial moderna. Essa é a compreensão da espacialidade que se busca, expressa na organização espacial e gerada a partir das relações entre as conexões existentes (ou não) dos espaços constituídos de determinado sistema espacial. Nesse sentido, consideramos o espaço a partir de sua organização espacial, em que o arranjo e a relação entre eles definem a natureza do todo. Com efeito, a organização espacial é investigada por meio do grau de relacionamento entre os ambientes, como estão sequenciados e conectados, ou seja, o que se liga a que, direta ou indiretamente, através de espaços intermediários.

Investigar a lógica do espaço interno que está por trás da caixa mural poderá levar a novas formas de compreensão da organização espacial da casa moderna brasileira e, em especial, da casa da década de 1970 de João Pessoa. Assim, as relações entre o continente (invólucro construído) e o conteúdo (organização espacial) são investigadas neste estudo.

Nessa perspectiva, a planta baixa tem papel fundamental, como instrumento de representação dos sistemas espaciais, traduzindo uma rede de espaços conectados por permeabilidades (portas, passagens, vazios), de modo a evidenciar as relações entre os espaços componentes do sistema e os elementos materiais que ordenam movimento, permitindo análises comparativas diretas entre os arranjos espaciais. Nesse sentido, os edifícios são entendidos como um intrincado de conexões que ordenam um vazio com a finalidade de separar ou conectar as atividades e as pessoas que as executam, e a planta representa essas conexões espaciais estruturadas que configuram a organização espacial. É através dessa estrutura espacial, da dimensão material, que a sociedade penetra e constitui o espaço arquitetônico.

O modo como se estabelecem essas conexões e as relações de influência e controle de determinado espaço sobre outro(s) pode ser observado na plantabaixa, pela configuração de seus espaços constituintes, definindo um instrumento fundamental para a compreensão do objeto arquitetônico sob ótica das relações espaciais.

\section{A amostra e como ela foi explorada}

Assumindo o cenário plural que caracteriza o contexto analisado, investigamos a correspondência entre tipos de estrutura 
espacial e tipos de caixa mural, ou seja, se os atributos formais e técnicos que definem a taxonomia (ARAÚJO, 2010) representam (ou determinam), de algum modo, a organização espacial das residências de João Pessoa. Portanto partimos de uma classificação definida e comparamos com aspectos espaciais evidenciados especificamente pela análise sintática.

As cinco vertentes têm características estéticas, elementos arquitetônicos e técnicas construtivas distintas entre si. No entanto acreditamos que existem padrões espaciais semelhantes (ou parentescos morfológicos) que unificam esse conjunto.Nesse sentido, procuramos demonstrar que a modernidade pode ir além da superfície construída das embalagens arquitetônicas.Nossa hipótese inicial é que, apesar da pluralidade que caracteriza os invólucros (às vezes, indo de encontro à linguagem de arquitetura moderna brasileira legitimada entre os anos 1940 e 1960), a organização espacial não distingue das práticas estabelecidas pela arquitetura moderna. Em outras palavras, estruturas espaciais semelhantes podem estar escondidas sob o disfarce de invólucros diversos.

Para a análise mais aprofundada dos atributos espaciais dessa produção, selecionamos um total de dezenove residências pertencentes às cinco vertentes para integrar nossa amostra (ver TAB. 1), com base em quatro critérios: localização (cinco bairros da cidade que agrupam $76,7 \%$ das casas dos anos 1970), área construída (entre 200,00 e 299,00 m²), arquitetos com mais de uma residência construída no período e quantidade suficiente de informações gráficas disponíveis sobre os projetos.

Tabela 1 - Distribuição das residências selecionadas por categoria

\begin{tabular}{l|c|c|c|c}
\hline Categorias & $\begin{array}{c}\mathbf{n .}^{\mathbf{}} \\
\text { casas }\end{array}$ & $\%$ & $\begin{array}{c}\mathbf{n .}^{\circ} \\
\text { casas } \\
\text { amostra }\end{array}$ & \% \\
\hline Residências “híbridas" (H) & 29 & 25,00 & 3 & 15,79 \\
\hline Legado moderno (LM) & 38 & 32,76 & 5 & 26,31 \\
\hline Arquitetura paulista (P) & 6 & 5,17 & 2 & 10,53 \\
\hline $\begin{array}{l}\text { Racionalização e pré- } \\
\text { fabricação (RP) }\end{array}$ & 12 & 10,35 & 3 & 15,79 \\
\hline Adequação ao clima (C) & 31 & 26,72 & 6 & 31,58 \\
\hline Total & 116 & 100,00 & 19 & 100,00 \\
\hline
\end{tabular}

Fonte: Elaborada pelas autoras.

A análise sintática do espaço é o campo de investigação que baliza a análise das propriedades configuracionais da organização espacial das casas, ou seja, investiga a organização espacial como um sistema de relações entre os espaços que a compõem (rede de espaços conectados). ${ }^{6}$ Hillier e Hanson (1984) defendem que como objetos sociais, os edifícios são uma fonte de informação sobre as sociedades que os criaram.A arquitetura é, portanto, tratada como constituída e constituinte das relações sociais no espaço. A análise sintática reúne um conjunto de técnicas e instrumentos de investigação dos atributos morfológicos do espaço com base na ob-
6. A partir de desdobramentos de teorias derivadas da Morfologia e da Matemática, a teoria da lógica social do espaço, proposta na década 1970 por Hillier, Hanson e colaboradores do University College of London (UCL), estabelece, pelo desenvolvimento de um corpo teórico-metodológico, a conexão entre estudos de cunho social e físico, com base na premissa de que a forma-espaço não está livre do conteúdo social. Os resultados dessa teoria foram reunidos no livro "The Social Logic of Space" (HILLIER; HANSON, 1984) e, a partir de então, vêm se desenvolvendo continuamente e enquadrando novas perspectivas de abordagem em diversas áreas de pesquisa(<http://www. spacesyntax.net/>). Hoje, estudos com enfoque na análise sintática estão disseminados por diversos centros e laboratórios de pesquisa no mundo. No Brasil, estão concentrados em grupos de pesquisa e programas de pós-graduação de universidades federais: Universidade de Brasília (Grupo de Pesquisa DIMPU - Dimensões Morfológicas do Processo de Urbanização); Universidade Federal do Rio Grande do Sul,em Porto Alegre (Pesquisa e Pós-Graduação em Arquitetura - PROPAR); Universidade Federal de Pernambuco, em Recife (Pós-Graduação em Desenvolvimento Urbano - MDU); e Universidade Federal do Rio Grande do Norte, em Natal (Grupo de Pesquisa MUsA - Morfologia e Usos da Arquitetura).

Cadernos de Arquitetura e Urbanismo, v.21, n.29, 2º sem. 2014 
servação das plantas baixas - através do sistema de barreiras (tudo aquilo que impede, dificulta ou desautoriza)e permeabilidades (tudo aquilo que proporciona, facilita ou incentiva) ao movimento -, possibilitando a representação e quantificação de suas propriedades espaciais.

As pesquisas que investigam a organização espacial com base nessa teoria envolvem os aspectos urbanos e arquitetônicos em que o tema residencial tem destacado interesse. ${ }^{7}$ Entretanto, o assunto ainda é pouco abordado no contexto de João Pessoa.Na Paraíba, os estudos acerca da arquitetura moderna tendem a abordar principalmente as cidades de João Pessoa e Campina Grande nos anos 1950-1960; os "anos heróicos" do modernismo, quando a arquitetura moderna representava não só uma nova linguagem de construção, mas também uma nova era para o País, que então acreditava estar caminhando rapidamente "em direção ao futuro". A difusão das experiências relativas ao habitar moderno, recentemente, está sendo discutida em pesquisas cujo foco está geralmente vinculado a três aspectos: (1) identificação dos edifícios, seus autores e agentes promotores; (2) compreensão do contexto em que a produção estudada se desenvolve sob as especificidades locais inseridas no contexto nacional; (3) análise em relação à caracterização/classificação formal dos edifícios.

Por um conjunto de técnicas e métodos, a análise sintática propõe a relação entre dois itens de conhecimento ou dois fenômenos que podem ser considerados espaciais: (1) a organização espacial (na escala urbana ou edilícia), considerando a ideia de sistema de barreiras e permeabilidades ao movimento (copresença), e opacidades e transparências à visão (cociência), cria campos de possibilidades e restrições de uso; (2) a estrutura social, os contatos e interações interpessoais entre categorias distintas de usuários (diferenciações sociais) através do sistema de encontros e esquivanças e estruturas de poder. Nesse sentido, o objetivo principal da análise sintática do espaço é compreender as relações entre a configuração espacial e a organização social, principalmente os efeitos da influência da forma-espaço ${ }^{8}$ nos padrões sociais a partir dos modos de uso, padrões de cociência, movimento e interação estabelecidos pelo sistema de barreiras e permeabilidades.

Para a teoria, interessa o espaço estruturado sistemicamente, ou seja, o espaço como um sistema de relações fundamentalmente topológicas e quantificáveis. Essa abordagem defende que as partes constituem o todo e são as relações e interações constituídas entre elas que definem suas propriedades. Isto é, o arranjo das unidades componentes do sistema define sua configuração espacial, portanto, se uma dessas unidades ou o modo de ela se relacionar com as demais for alterado, as propriedades que caracterizam o todo se modificam. Assim, o foco é compreender as propriedades do sistema espacial e não as propriedades individuais dos espaços componentes.

As técnicas da sintaxe espacial permitem, a partir da decomposição analítica dos espaços constituintes, a identificação e quantificação de atributos físicos do sistema por meio de três unidades espaciais que se aplicam a objetos espacialmen-
7. Acerca do tema sob essa abordagem teórica, ver pesquisas de Luiz Amorim e colaboradores, que desenvolvem estudos no Programa de Pós-Graduação em Desenvolvimento Urbano (MDU) da UFPE; e Edja Trigueiro e colaboradores, no Programa de Pós-Graduação em Arquitetura e Urbanismo (PPGAU) da UFRN.
8. Neste estudo, utilizaremos o termo "forma-espaço" empregado por Holanda (2002), para descrever o modo como se estruturam e relacionam os espaços de um determinado objeto arquitetônico, para diferenciar do termo "forma", usualmente vinculado em arquitetura à aparência ou à natureza do invólucro construído de uma edificação (comumente associado à noção de estilos arquitetônicos), ou ainda, como descrição relativa a seus aspectos geométricos. São empregados como sinônimos de forma-espaço: configuração espacial, organização espacial e estrutura espacial. 
te distintos: (1) linhas axiais ${ }^{9}$, (2) polígonos convexos ${ }^{10}$ e (3) campos visuais. ${ }^{11}$ A convexidade é, por definição, a técnica de representação configuracional que mais se adéqua ao objeto analisado neste estudo e foi utilizada como método de representação da dimensão sintática dos edifícios residenciais.

Consiste em desenhar as unidades convexas (polígonos) sobre a planta baixa dos edifícios e conectá-las, considerando as permeabilidades (portas, passagens, vazios) entre elas.Os espaços convexos, por sua vez, podem ser representados em grafos. Os grafos são estruturas de representação derivadas da teoria dos grafos, utilizados para descrever qualquer sistema, em particular sistemas em rede. Na análise sintática, os grafos evidenciam as conexões entre os espaços componentes do sistema e suas propriedades: integração, profundidade, distributividade, simetria, conectividade. Os círculos (ou nós) representam os espaços e as linhas (ou vértices), as relações de permeabilidades (conexões, passagens, vãos, cruzamentos) entre eles (HANSON, 1998). Os grafos são empregados como procedimentos que permitem análises comparativas diretas entre os arranjos espaciais dos objetos e suas relações internas.

Para facilitar a "leitura" e, principalmente, para tornar algumas propriedades sintáticas facilmente perceptíveis, é possível alinhar (justificar) um grafo a partir de um nó, chamado de nó raiz. Assim, os grafos justificados (construídos com auxílio do aplicativo JASS) ${ }^{12}$ representam os acessos com base em um determinado espaço tomado como referência e capturam as propriedades topológicas da configuração espacial, definindo "um modo de análise que combina a'decifração' visual de padrões com procedimentos de quantificação" (HILLIER; HANSON, 1984, p.149) 13 $^{13}$ (FIG.2). A ideia de percurso (passos na distância topológica) de um ponto de partida (origem) a um ponto de chegada (destino) através de espaços intermediários permeáveis e as relações de influência e controle de cada espaço sobre seus adjacentes dentro do sistema podem ser representadas e observadas no grafo justificado, por meio da configuração de seus elementos (nós e linhas).

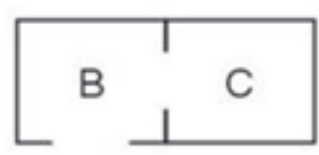

A

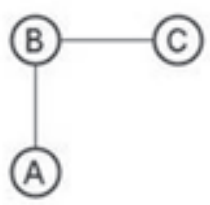

A análise da organização espacial das residências foi considerada com base em três sistemas espaciais distintos (FIG.3 e 4): (1) viver mínimo e exterior, representa todo o sistema de espaços interiores ligado ao exterior através de todos os acessos descritos na planta (justificado a partir do exterior, "lado de fora"); (2) viver mínimo, representa apenas o sistema de espaços internos em uma tentativa de compreender as propriedades do sistema com base na eliminação das conexões externas (justificado a partir do ponto externo mais próximo à entrada social da resi-
9. As linhas axiais representam as linhas de movimento e visibilidade especialmente dos espaços urbanos, com base no desenho de segmentos de reta sobre as permeabilidades (ruas, avenidas, parques, praças) da malha urbana. O conjunto de linhas axiais compõe o mapa axial.

10. Polígonos convexos são representações bidimensionais utilizadas para descrever sistemas que se configuram em espaços convexos, principalmente edifícios (áreas definidas por polígonos). Espaços convexos são espaços em que a área interior é visível de todos os pontos e uma linha reta traçada sobre eles deve cruzar apenas dois segmentos de seus perímetros.

11. Os campos visuais são representações das isovistas a partir de um determinado ponto no espaço, utilizados para medir o potencial de visibilidade entre atores e ambientes.

12. JASS. Elaborado por BERGSTEN, L. et al. v1.0, 21 maio 2003, GNU-General Public License.

13. Do original: "[...] allow a form of analysis that combines the visual decipherment of pattern with procedures for quantification" (HILLIER; HANSON, 1984, p.149).

Figura 2 • Relação entre estrutura espacial e grafo justificado. Grafo justificado a partir do exterior (A). O espaço B (permeável) controla o acesso entre A e C.

Fonte: Hanson, 1998 (editado pelas autoras).

Cadernos de Arquitetura e Uthanismo, v.21, n.29, 2" sem. 2014 
dência, geralmente o terraço); (3) grafo dos setores, representa o agrupamento dos espaços de acordo com o setor funcional (social, serviço e privado) (AMORIM, 1999).

\section{RESIDÊNCIA VIRGÍNIO VELOSO FREIRE FILHO}

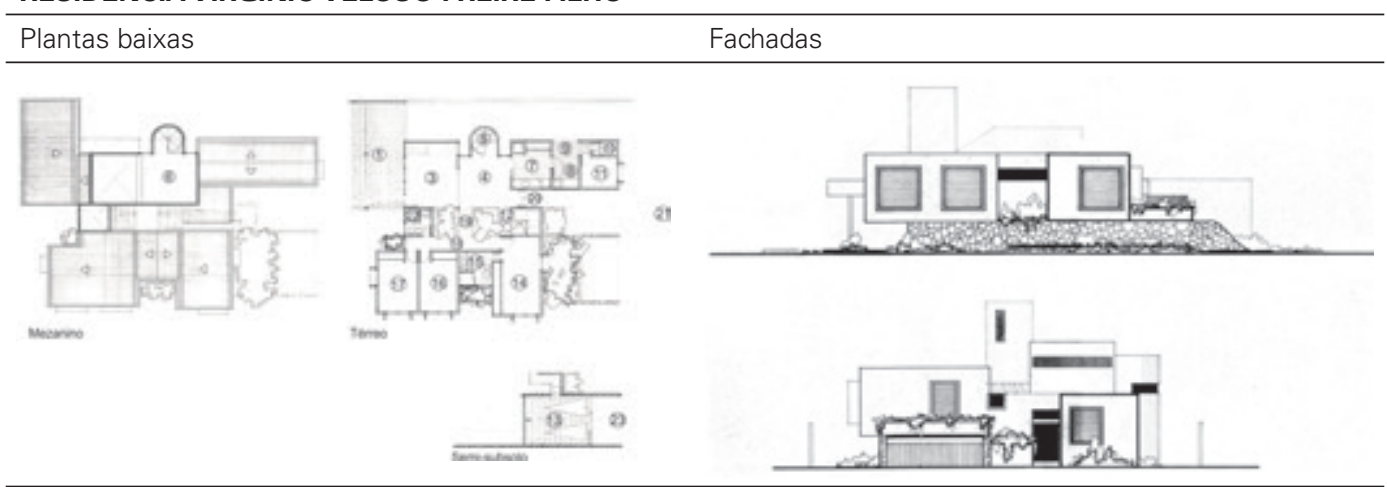

Legenda: (1) terraço, (3) estar, (4) jantar, (5) escada helicoidal, (6) escritório, (7) cozinha, (8) área serviço, (9) circulação serviço, (10) banheiro empregados, (11) quarto empregados, (12) escada garagem, (13) garagem, (14) quarto principal, (15) banheiro, (16) quarto, (17) quarto, (18) corredor, (19) escada, (20) hall entrada, (21) exterior, (22) banheiro, (23) rampa garagem.

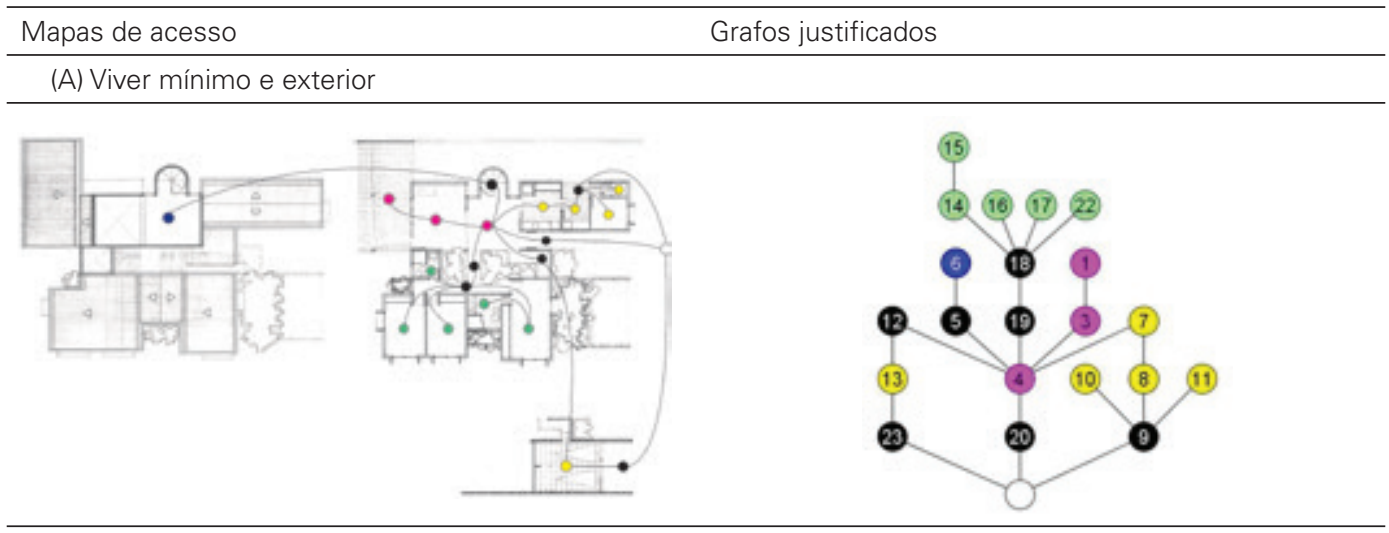

(B) Viver mínimo
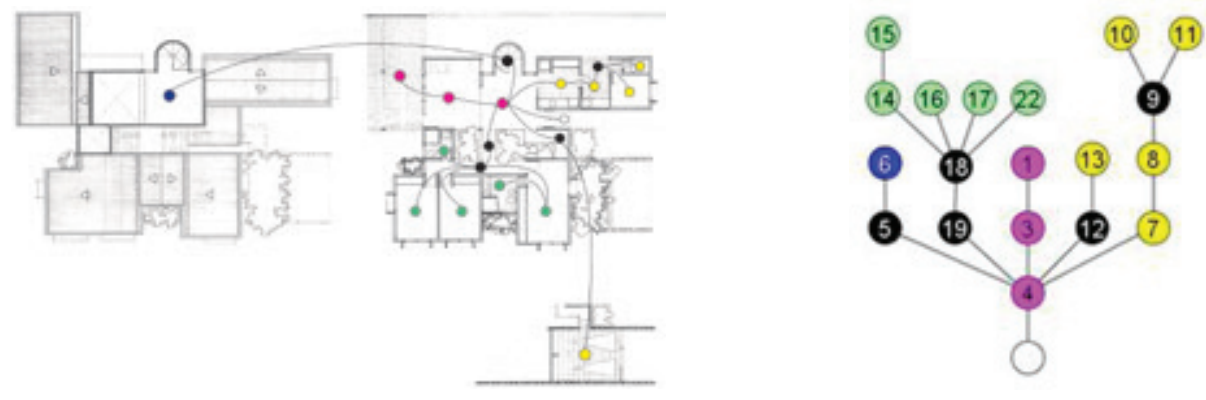

Figura 3 • Exemplos de análise configuracional

Fonte: Aldrigue, 2012. 

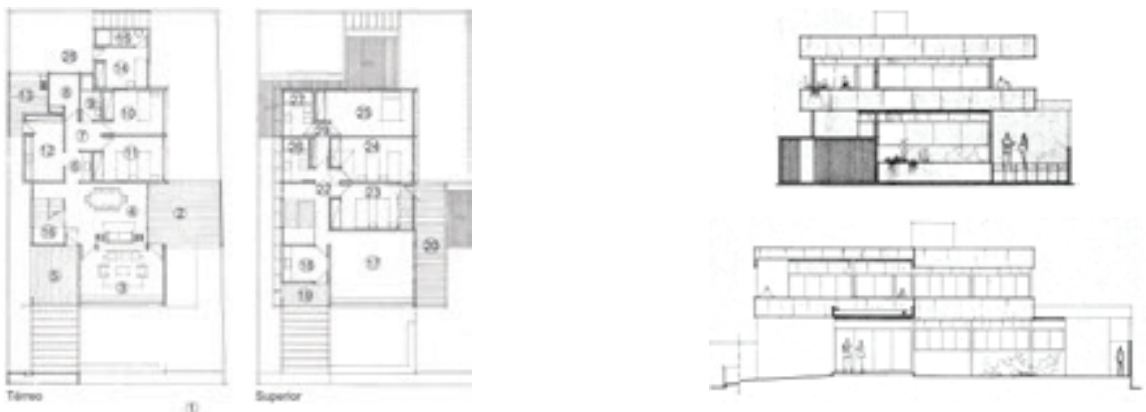

Legenda: (1) exterior, (2) terraço, (3) estar, (4) jantar, (5) garagem, (6) lavabo, (7) circulação, (8) sala costura, (9) banheiro social, (10) quarto hóspedes, (11) quarto, (12) cozinha, (13) área serviço, (14) quarto empregados, (15) banheiro empregados, (16) escada, (17) estar íntimo, (18) copa, (19 e 20) varanda, (22) corredor, (23) quarto, (24) quarto, (25) quarto principal, (26) banheiro, (27) banheiro, (28) circulação, (29) hall suíte.

\begin{tabular}{l} 
Mapas de acesso \\
\hline (A) Viver mínimo e exterior
\end{tabular}

(B) Viver mínimo
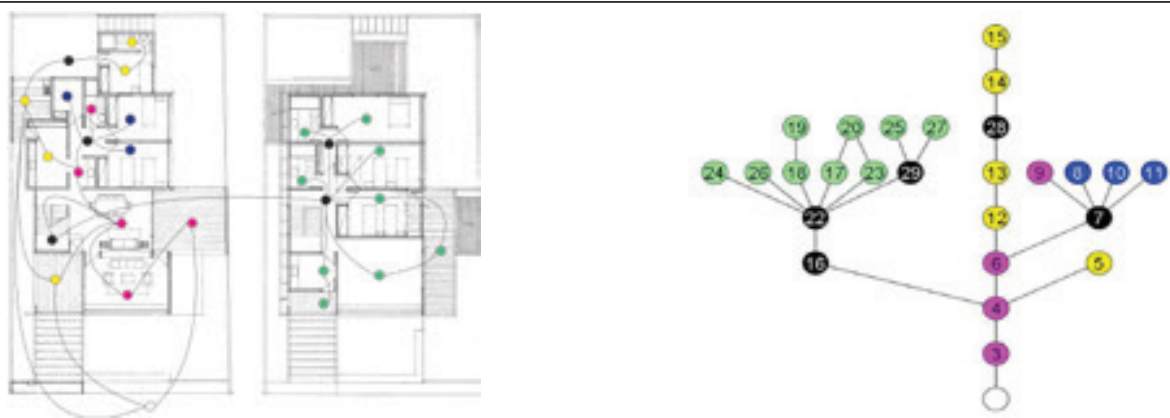

Figura 3 • Exemplos de análise configuracional

Fonte: Aldrigue, 2012. 


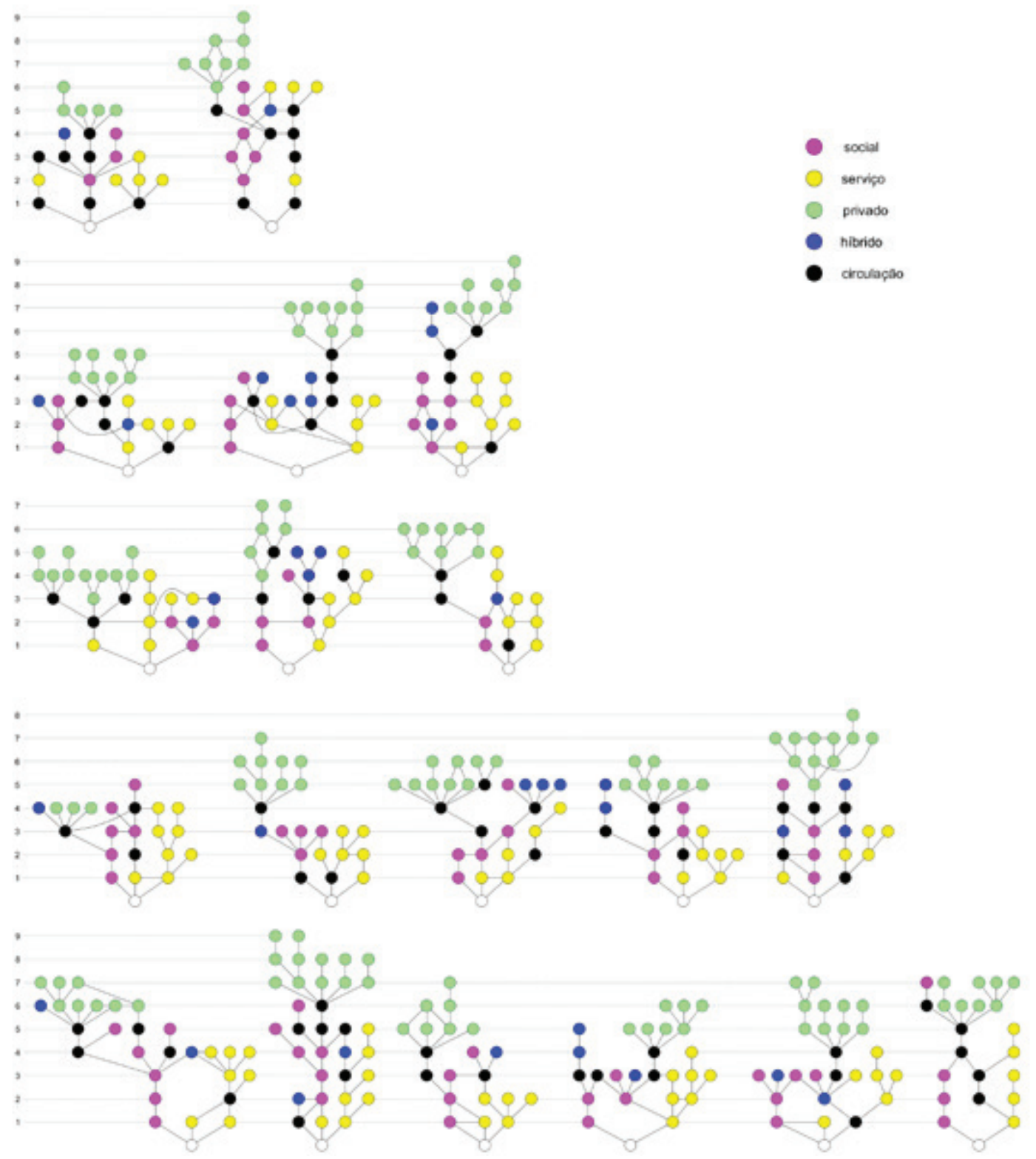

Figura 4 • Grafos "viver mínimo e exterior" das residências analisadas

(1) Virgínio V. Freire Filho, (2) Gualberto Chianca, (3) Antônio de Pádua G. Pereira,

(4) Lino Borges, (5) Damião L. Lima, (6) Aloízio Carneiro, (7) Luciano L. Wanderley,

(8) Maria Auxiliadora M. Maroja Garro, (9) Antônio da Silva Morais, (10) Rubens P. Barreto, (11) Jacy Cavalcanti, (12) William V. da Silva, (13) Edvaldo Fernandes Motta,

(14) Luiz Régis P.de Farias, (15) José Ari G. do Amaral, (16) Potengi H. de Lucena,

(17) Francisco de Sales Pinto, (18) Romualdo Francisco Urtiga, (19) Alcindo Lima

Filho. As cores indicam os setores: (rosa) social, (verde) íntimo, (amarelo) serviço, (azul) híbrido ${ }^{14}$, (preto) circulação.

Fonte: Aldrigue, 2012.
14. Esse setor foi assim denominado por relacionar os espaços que têmduas (ou mais) funções descritas na planta baixa (escritório/quarto de hóspedes, por exemplo). 


\section{Os achados}

Pela análise comparativa da organização espacial das 19 residências,foi possível observar que, em geral, as casas têm esquemas espaciais muitos semelhantes entre si. Essas características são compatíveis com aquelas apresentadas pela literatura como associadas à produção residencial moderna brasileira, revelando uma relação direta entre a casa moderna e as analisadas no estudo independente do invólucro construído. O que se percebe é que as práticas modernas continuam na década de 1970, estabelecendo as regras do arranjo espacial. Algumas dessas características recorrentes são descritas a seguir:

- Ainda que a casa moderna apresentasse profundas mudanças espaciais oriundas das transformações sociais em curso, algumas práticas eram tão fortemente arraigadas à herança doméstica brasileira que permaneceram quase inalteradas.Essas referências históricas, associadas aos usos e costumes arraigados à família brasileira,estavam tão impregnadas na estrutura espacial do programa residencial que a arquitetura moderna acabou por reproduzi-las. Nesse sentido, ainda que, no geral, a arquitetura moderna tenha permitido ou induzido mudanças em muitos aspectos do modo de vida brasileiro, a interface entre os usuários domésticos (patrões, visitantes e empregados) é muito similar à do sistema patriarcal anterior. Se, de um lado, os modelos formais, os materiais, os eletrodomésticos e o zoneamento setorial provocaram mudanças, por outro, os padrões sociais de controle e supervisão familiar e a diferenciação econômico-espacial entre patrões e empregados ainda se faziam presentes na estrutura espacial moderna. Assim, no que tange à organização espacial, o conflito entre tradição e modernidade foi solucionado pela combinação de arranjos espaciais novos e preexistentes.

- A organização espacial definida em setores funcionais (social, serviço e íntimo) na arquitetura moderna introduziu a preocupação com a divisão racional das atividades na lógica espacial residencial. Cada espaço deveria ser agrupado e conectado aos demais de acordo com sua função, visando a estabelecer a melhor articulação espacial dos setores entre si. Essa prática determinou a base da organização espacial da casa moderna. Em geral, os setores se organizam estabelecendo zonas relativamente independentes: o setor de serviço, isolado, garantindo certa autonomia das atividades domésticas ao mesmo tempo em que possibilita a separação dos espaços destinados exclusivamente aos empregados (dependência); o setor social, mais amplo e flexível, exerce o papel de mediar e controlar acessos entre os espaços íntimos e de serviço, e articula o contato entre os três grupos de usuários em momentos específicos da rotina doméstica (setor de transição); e o setor íntimo, isolado, garantindo a privacidade familiar.Essa comunicação entre os três principais setores domésticos aponta a existência de uma clara distinção entre visitantes, moradores e empregados que se materializa no arranjo espacial da casa moderna brasileira por meio da posição que cada grupo ocupa na dinâmica social, de modo que a setorização funcional define 
um modo de estruturação dos espaços domésticos baseado nas práticas sociais. Esse princípio de desenho, aliado ao modo como os setores são organizados com referência aos parâmetros climáticos de ventilação e insolação, podem ser considerados os principais mandamentos da configuração espacial das casas modernas (AMORIM, 1999), bem como a principal distinção entre estas e suas antecessoras.

Esse padrão de arranjo espacial se repetia independentemente da condição socioeconômica da família. Na década de 1970, a classe média passou a ter acesso aos serviços de arquitetura. Esses novos clientes, mais presentes nas tarefas domésticas, demandavam soluções espaciais mais adequadas a essa realidade:residências e modos de vida mais práticos, nos quais havia menor número de empregados e, principalmente, não havia empregados-moradores. No entanto, mesmo em programas mais compactos, aqueles que continham apenas os espaços mínimos, ficava evidente que as soluções configuracionais expressas no arranjo espacial manifestavam a intenção de separar moradores e empregados por meio de espaços intermediários, enfatizando que algumas regras sociais se impunham sobre as diversas condições socioeconômicas.

- A posição relativa do quarto de empregados como espaço mais segregado (isolado)da organização espacial doméstica (topologicamente separado daqueles de uso dos visitantes e, principalmente, de uso exclusivo da família,e,muitas vezes, situado fora dos perímetros da habitação, apresentando maior número de conexões com áreas externas que internas)é uma circunstância solidamente estabelecida no espaço residencial brasileiro. A casa reproduz padrões sociais, impondo ao espaço doméstico uma complexidade de circulações e espaços intermediários (de transição) que materializa a distância entre patrões e empregados através do seu sistema de barreiras e permeabilidades. É a relação de acessos, controle e (des)encontros entre patrão-empregado que determinará essa conexão e seus limites: espaços que "podem" oferecer essa interface, como sala de jantar (ou copa, quando existente), aproximam-se; aqueles que não, distanciam-se. Nesse arranjo, a sala de jantar exerce um papel articulador na lógica espacial interna das residências, muitas vezes interligando os três setores. Essa é uma herança que data de meados do século XIX em algumas esferas sociais e do início do século XX em quase todos os lugares no País (TRIGUEIRO, 1994).

- Na outra extremidade (considerando a distância topológica)do complexo espacial doméstico, a família. O isolamento dos espaços íntimos, em especial do quarto do casal, aponta o início de um processo que se intensifica na contemporaneidade. Na casa moderna, a exigência de privacidade levou à segregação desses espaços em relação aos demais setores. Quartos abrindo-se diretamente para salas de estar e jantar ou conectando-se uns aos outros (como pode ser observado em casas pré-modernas) literalmente desapareceram após a década de 1950. Essa configuração aponta para novos requisitos de privacidade, não só da família, mas também entre seus membros. ${ }^{15}$ Essa tendência
15. Nesse momento, uma transição começa a ocorrer e vai se consolidar na casa contemporânea: a privacidade que antes era da família como um todo, ou seja, a família como um subgrupo da sociedade à qual o sujeito estava subordinado, transfere-se para o indivíduo, de modo que estee suas particularidades passam a ser mais importantes (valorização do sujeito); cada um tem sua própria vida, muitas vezes independente da vida familiar. Essas mudanças se transferem para o arranjo espacial conforme os quartos definem em si zonas de pertencimento de um habitante (GRIZ; AMORIM; LOUREIRO, 2008, p.39-40).

Cadernos de Arquitetura e Urbanismo, v.21, n.29, 20 sem. 2014 
é ainda mais evidente nas casas de famílias mais abastadas: quanto mais favorecida economicamente a família, menos os habitantes compartilham os mesmos cômodos (quartos e banheiros).

- A relevância do exterior como integrador do sistema espacial é uma característica histórica dos lares brasileiros (TRIGUEIRO, 1994) e torna-se ainda mais patente na estrutura espacial doméstica com a arquitetura moderna. Essa premissa é claramente observada quando consideramos apenas os espaços internos (sistema viver mínimo). A eliminação do exterior apresentou alterações significativas nas relações entre os espaços componentes do sistema espacial alterando sua configuração. Os espaços internos, principalmente sociais e de serviço, perdem as conexões com os externos, restringindo as possibilidades de percurso (rotas) entre determinados espaços, representando, de um lado, a relevância da integração exterior-interior para a arquitetura moderna e, de outro, o controle de acessibilidade que determinados espaços-chave exercem sobre a circulação interna. Nesse sentido, o menor número de rotas limita escolhas de percurso e, consequentemente, torna o sistema mais inflexível, diminuindo as possibilidades de encontros e interações interpessoais.

- A continuidade espacial, uma das premissas mais difundidas da arquitetura moderna, representada na organização espacial doméstica principalmente pela união das salas de estar e jantar em um ambiente único, confere ao setor social maior dinamismo. A aproximação dos espaços de uso da família e de receber visitantes no setor social (atividades que passam a ser realizadas em um único espaço após o desaparecimento das dependências de uso exclusivamente familiar) indica a adoção de um modo de vida mais informal e prático na relação entre visitantes e família. No entanto essa continuidade espacial permanece restrita a determinados ambientes, cuidadosamente pensados para tal, representando (afinal, a casa é o palco da vida familiar) a incorporação de comportamentos modernos pela família. Assim, a configuração espacial do setor social contrasta com a reclusão do setor íntimo. "Continuidade e controle parecem ser peças de jogos diferentes, mas a residência moderna parece mostrar como podem ser combinados" (AMORIM, 2008, p.317). Se, de um lado, os espaços sociais expõem a intimidade desejada, expressão da modernidade da família, que passa a conviver de modo mais direto com os visitantes, por outro, os setores íntimos se deslocam para uma zona isolada por uma sequência de espaços de transição que definem uma única rota de acesso, indicando quem pode ou não ter passagem.

- A continuidade espacial adquire um novo sentido na casa moderna quando observada em termos de visibilidade. As estratégias compositivas do espaço interno moderno criam uma dinâmica visual por meio das mudanças de níveis alcançados por rampas e escadas, e planos verticais transparentes. Estratégias espaciais, como mezaninos, vazios verticais, patamares que se prolongam em "semipavimentos" para comportar atividades de transição (estú- 
dio, escritório, salas de televisão) e portas de vidro abertas para pátios e terraços, geraram perspectivas visuais que possibilitam diversas apreensões do interior (continuidade visual). Movimento e visão fazem parte da mesma experiência de percepção do espaço arquitetônico moderno. O movimento também é um conceito importante para Hillier e Hanson (1984) na compreensão do objeto arquitetônico como entidade espacial, quando entendem que a espacialidade está intrinsecamente ligada ao movimento. É pelo caminhar (com pés no chão) que apreendemos o espaço. Esse entendimento se relaciona diretamente com a ideia da copresença: para interagir (ou não) com usuários distintos, é necessário encontrá-los (ou evitá-los), e esses encontros e desencontros se fazem no plano arquitetônico, seja da cidade ou do edifício.

- A multiplicidade de acessos distribuídos nos limites entre espaço público (rua) e espaço privado (lote) é outra característica das casas modernas brasileiras. Os acessos são distribuídos geralmente em: pedestre social (moradores/ visitantes) e serviço (empregados), e veículos. Assim, o cruzamento de empregados e moradores fica restrito às situações desejadas, revelando questões de cunho social. Em alguns casos, pelas especificidades econômicas (casas de famílias menos abastadas) e dimensões do terreno, os acessos social e de automóveis ${ }^{16}$ ou de serviço e de automóveis podem se fundir, mas o mesmo dificilmente ocorrerá com os acessos social e de serviço, este geralmente apartado e, às vezes, escondido nos limites do muro por reentrâncias ou vegetação.O mesmo raciocínio é empregado no interior da edificação, onde o sistema de circulações independentes garante o "bom" funcionamento das atividades domésticas, evitando encontros não programados entre visitantes, habitantes e empregados. Em casas de maior poder aquisitivo, observa-se a existência de acessos (escadas e corredores) que conectam diretamente o setor de serviço ao íntimo.

\section{Continente versus conteúdo ou continente $\&$ conteúdo?}

Nossos achados indicam que, apesar da aparência externa variada, as estratégias espaciais percebidas na estrutura de barreiras e permeabilidade se assemelham. A comparação entre essas residências não corresponde a uma mudança significativa no contexto da organização espacial, de modo que as relações encontradas entre invólucro construído e espaço não são diretas, intrínsecas. A pluralidade da superfície construída revela "expressões epidérmicas" que parecem não se aprofundar no espaço. Assumimos, portanto, que caixas murais distintas podem guardar configurações espaciais semelhantes.

A análise sintática apontou que as residências chamadas de "híbridas", aquelas que apresentam um aparente deslocamento dos pressupostos modernos em prol de uma retomada dos elementos "coloniais", têm organizações espaciais cujas características convergem com as demais categorias analisadas, aquelas que compõem expressões legitimadas da arquitetura
16. Nessas casas, a garagem pode transformar-se em abrigo de utilização dupla: guarda de automóvel e varanda, de acordo com a necessidade. 
moderna. Os resultados mostraram que aspectos estéticos não foram capazes de influenciar os sistemas espaciais, assim como não os determinam. Nesse sentido, podemos entender que as distintas "aparências" não conseguem descolar-se do modo corrente de "organizar o espaço" ou de "construir o edifício". De fato, no âmbito da organização espacial, pouco importa se uma casa é formalmente identificada como moderna ou "coloniosa". Podemos, portanto, afirmar que, espacialmente, essas residências apresentam características modernas.

A arquitetura moderna transformou definitivamente os esquemas espaciais precedentes, constituindo um modelo de concepção abstrato que poderia ser a "base" para caixas murais distintas; inclusive essa era a proposta do projeto moderno, um mesmo programa e uma mesma estrutura espacial podiam corresponder a diferentes resultados plásticos (dependendo da cultura, dos materiais, recursos estruturais, tecnológicos, etc.), de modo que sua fisionomia externa pode se relacionar com modelos historicistas, mas abarcar uma organização espacial tipicamente moderna, em sua concepção. Acreditamos que, apesar da diversidade da produção, a assimilação dos esquemas espaciais modernos já estava consolidada como prática projetual e foram aplicados independentes da intenção plástica, revelando o descolamento entre invólucro e espaço. Nesse sentido, as casas analisadas demonstraram que, na década de 1970, as premissas de concepção espacial difundidas nas escolas de Arquitetura em todo País nas décadas anteriores e resultantes da aceitação e da interpretação dos princípios modernos permanecem tão fortes ou ainda mais fortes, talvez, do que nos anos anteriores.

O fato é que a organização espacial responde mais lentamente às mudanças ou aos "modismos" do que o invólucro construído. Esse aspecto está intimamente ligado à dimensão social que guarda o espaço. Em outras palavras, modos de vida estão menos suscetíveis a mudanças, já que dependem de transformações na estrutura de valores sociais, que são incorporadas com menor agilidade às residências. Nesse sentido, a difusão do "morar moderno" é mais abrangente do que se supunha inicialmente (ao observar apenas o invólucro das residências) já que perpassa, com maior ou menor fidelidade, todos os casos analisados. Esses achados revelam que a produção arquitetônica local define certa unanimidade de composição espacial baseada nas variadas práticas estabelecidas pela arquitetura moderna, ou seja, nas premissas modernas de compor o espaço.

A abordagem aqui proposta começa a desvendar esse processo,evidenciando aspectos até então não revelados dessa produção, conforme aprofunda a análise para além da aparência, investigando as regularidades e divergências subjacentes à sua concepção. A noção de que apenas (ou predominantemente) a concepção plástica pode definir, caracterizar ou explicar um período da produção arquitetônica não sintetiza a experiência moderna, já que seus princípios fundadores não se resumem à percepção visual externa de seus edifícios, mas também à sua dimensão espacial. 
Entretanto a diversidade de expressões nos invólucros construídos e a similaridade na configuração espacial constatadas na amostra também estão relacionadas a outros aspectos não analisados neste estudo. Além da questão estrutural da redefinição econômica do capitalismo, entre outras, há uma disciplinar que diz respeito à crítica/renovação da arquitetura moderna e que incentiva propostas de novos caminhos ou alternativas e, portanto, experimentações. Outra, mais prosaica, está relacionada aos "modismos", em que o cliente e, ou, o arquiteto aparecem como agentes fundamentais no processo de definição da aparência do edifício. Essas duas questões, que estão na base da explicação para o fenômeno, seriam respostas a uma demanda específica em determinado contexto. A segunda explicaria perfeitamente essa dissonância entre "invólucro" versus "organização social", porém a primeira provavelmente deveria desembocar em nova proposta de configuração espacial, como de fato aconteceu em alguns casos. Entretanto, no caso das residências individuais, prevalece o modelo hegemônico de meados do século XX. Essas possibilidades combinatórias entre variáveis que mesclam características configuracionais, aspectos sociais e desejo dos usuários apontam para as possíveis "causas" do quadro identificado na produção arquitetônica de João Pessoa da década de 1970.

O intuito (que foi apenas iniciado nesta pesquisa) é conhecer essa produção em todos os seus aspectos para não correr o risco de exaltar ou repudiar, seja pela proximidade e similaridade ou pelo distanciamento e particularidade, a arquitetura moderna brasileira de renome internacional. O estudo desse tema baseou-se na premissa de que a análise dos aspectos formais dessa produção encobria outros tantos aspectos que precisariam ser mais bem discutidos.

\section{Referências}

ALDRIGUE, Maryá de Sousa. Aparências da forma e forma do espaço: análise da configuração espacial de residências unifamiliares dos anos 1970 em João Pessoa-PB. 2012. 260f. Dissertação (Mestrado em Arquitetura e Urbanismo) - Programa de Pós-Graduação em Arquitetura e Urbanismo, Universidade Federal do Rio Grande do Norte, Natal, 2012.

AMORIM, Luiz Manuel do Eirado. Flexibilidade espacial: entre o princípio e o mito. In: AMORIM, Luiz; GRIZ, Cristiana (Org.). Cidades: urbanismo, patrimônio e sociedade. Olinda: Livro Rápido, 2008, p. 297-326.

AMORIM, Luiz Manuel do Eirado. The Sectors' Paradigm: a study of the spatial and functional nature of modernist housing in Northeast, Brazil. 1999.438 f. Tese (PhD Advanced Architectural Studies) - The Bartlett School of Graduate Studies, University College of London, Londres, 1999.

ARAÚJO, Ricardo Ferreira de. Arquitetura residencial em João Pessoa-PB: a experiência moderna nos anos 1970. 2010. 301 f. Dissertação (Mestrado em Arquitetura e Urbanismo) Universidade Federal do Rio Grande do Norte, Natal, 2010. 
ARAÚJO, Ricardo; TINEM, Nelci; COTRIM, Marcio. Arquitetura residencial moderna em João Pessoa nos anos 1970. Arquitextos, São Paulo, n. 126.03, nov. 2010. Disponível em <http:// www.vitruvius.com.br/revistas/read/arquitextos/11.126/3651>. Acesso em: 6 dez. 2010.

BASTOS, Maria Alice Junqueira. Pós-Brasília: rumos da arquitetura moderna brasileira. São Paulo: Perspectiva, 2007.

GRIZ, Cristiana; AMORIM, Luiz; LOUREIRO, Claudia. A família e a casa: papai ainda sabe tudo? Cadernos de Arquitetura e Urbanismo, Belo Horizonte, v. 15, n. 16, p. 29-47, 2008. Disponível em: <http://periodicos.pucminas.br/index.php/Arquiteturaeurbanismo/article/view/960/1004>. Acesso em: 6 out. 2010.

HANSON, Julienne. Decoding homes and houses. Cambridge: Cambridge University Press, 1998.

HILLIER, Bill; HANSON, Julienne. The social logic of space. Cambridge: Cambridge University Press, 1984.

HOLANDA, Frederico de. O espaço de exceção. Brasília: Ed. Universitária/UnB, 2002. (Arquitetura e Urbanismo).

TRIGUEIRO, Edja. Change (and continuity) in domestic space design. 1994. Tese (Doutorado em Advanced Architectural Studies) - The Bartlett School of Graduate Studies, University College of London, Londres, 1994.

Recebido em 21/08/2014 Aprovado em 05/12/2014 
Cadernos de Arquitetura e Urbanismo, v.21, n.29, 2" sem. 2014 